Research Paper

\title{
Experimental and analytical study on liquid and vapor penetration of high- reactivity gasoline using a high-pressure gasoline multi-hole injector
}

\author{
Jianguo Du ${ }^{\mathrm{a}}$, Balaji Mohan ${ }^{\mathrm{a}, *}$, Jaeheon Sim ${ }^{\mathrm{b}}$, Tiegang Fang ${ }^{\mathrm{c}}$, William L. Roberts \\ ${ }^{a}$ Clean Combustion Research Center, King Abdullah University of Science and Technology, Thuwal, Makkah Province, Saudi Arabia \\ ${ }^{\mathrm{b}}$ Fuel Technology Division, R\&DC, Saudi Aramco, Dhahran, Eastern Province, Saudi Arabia \\ ${ }^{\mathrm{c}}$ Department of Mechanical and Aerospace Engineering, North Carolina State University, Raleigh, NC 27695, United States
}

\section{H I G H L I G H T S}

- Penetration lengths for high-pressure GCI injector and GCI fuel were studied.

- Liquid penetration length was longer under high EGR condition.

- Penetration length regression models showed good agreement with experiments.

\section{A R T I C L E I N F O}

\section{Keywords:}

Fuel spray

High reactivity fuel

Penetration correlation

Liquid and vapor phase

\begin{abstract}
A B S T R A C T
Spray penetration length is an important parameter which is of great interest to both experimentalists and modelers. As it affects engine efficiency and emissions, measurement and prediction of spray penetration can significantly benefit engine optimization under various operating conditions. In this study, penetration length was investigated in a pre-burn constant volume combustion chamber using a gasoline multi-hole injector with high reactivity gasoline-like fuel designed explicitly for gasoline compression ignition (GCI) engines. Diffused back illumination (DBI) and shadowgraph were implemented for liquid and vapor phase penetration measurements, respectively. Different pre-burn gas mixtures are compared to investigate the influence of ambient gas properties on gasoline spray penetration under evaporating conditions. The liquid penetration under the gas composition of higher molecular weight tends to be longer. However, the vapor penetration showed insignificant effect under different gas compositions. Ambient gas temperature and gas composition were found to be an essential parameter for liquid phase penetration. Pressure difference was found to affect the vapor penetration length while its influence on liquid phase steady state penetration length at high ambient gas temperature is marginal. Statistical analysis was performed for both liquid and vapor phase penetration lengths, and a prediction model was developed with good agreement to the data under all test conditions.
\end{abstract}

\section{Introduction}

Gasoline compression ignition (GCI) engines have a high potential to increase engine efficiency and reduce emissions [1-3]. For manufacturers, development activities concerning designing and optimizing the new engine concept, CFD simulation is not only practical but also required [4]. Spray modeling contributes to one of the main uncertainties in engine CFD simulations [5]. Thus validation of spray models through experiments is of great importance for simulation fidelity.

Spray penetration length is a crucial characteristic which affects engine efficiency and emission performance. Over penetration might cause impingement on the walls, thus leads to increased emission and reduced fuel efficiency while shorter penetration results in insufficient fuel-air mixing [6,7]. Optimization of spray penetration length for a specific engine combustion chamber geometry is mandatory to obtain optimum engine performance [8]. Therefore, spray penetration length is widely used for spray model calibration.

Many factors influence the transient behavior of spray penetration length. Commonly investigated parameters are injection pressure, ambient gas density, fuel properties, and nozzle geometry. For a diesel spray, predictive models for cold liquid jet penetration length were developed by researchers using single hole nozzles [9-11]. The work of Wang et al. [12] shows that single-hole diesel and bio-diesel spray

\footnotetext{
* Corresponding author.

E-mail address: balaji.mohan@kaust.edu.sa (B. Mohan).
} 


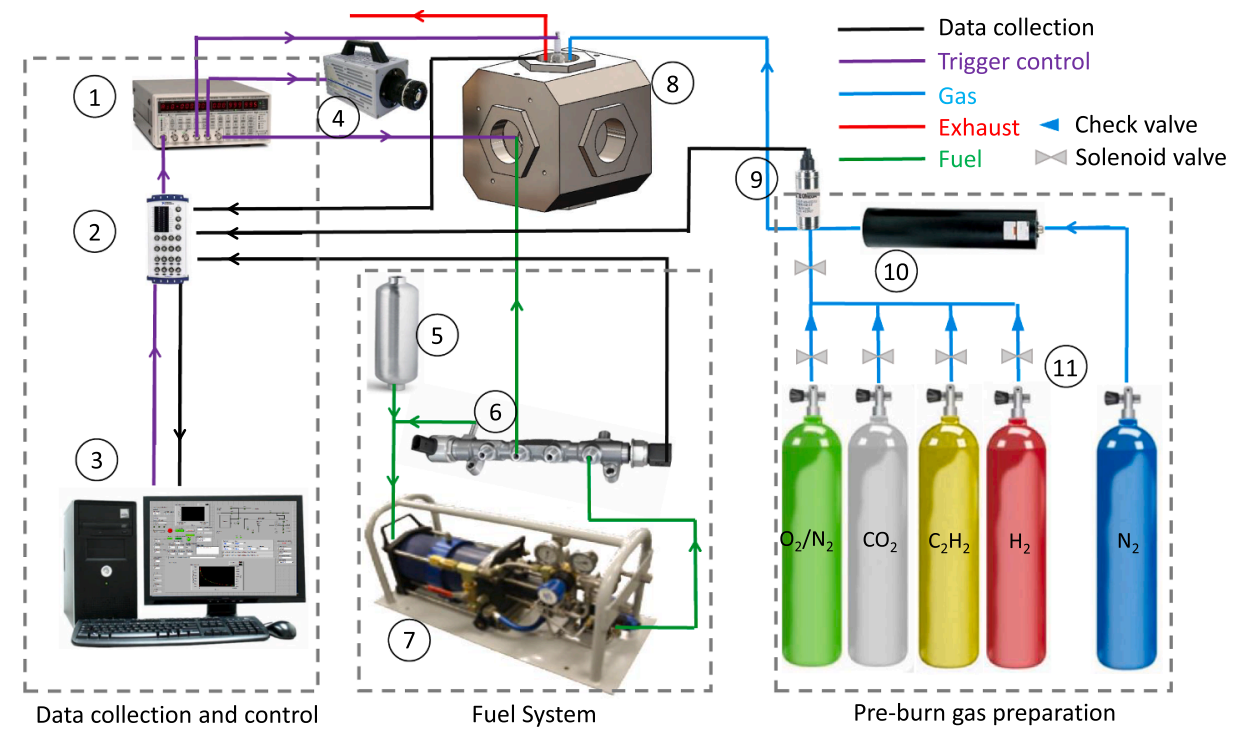

Fig. 1. Schematic of pre-burn type Constant Volume Combustion Chamber (CVCC).

liquid penetration length at ambient room temperature is proportional to $t^{1 / 2}$ even at ultra-high injection pressure conditions. The correlation for vapor penetration length under hot conditions also has been established for the engine combustion network (ECN) spray D injector [13]. Payri et al. [14] developed models for diesel spray liquid and vapor phase penetration length at evaporative conditions. Dent [9] included ambient gas temperature's influence into liquid penetration correlation, but the model is a single equation for the entire injection duration. These correlations were developed based on single hole diesel spray, which does not fit with gasoline multi-hole sprays. Zeng et al. [15] developed empirical correlation by dimensional analysis for GDI spray penetration length at $1 \mathrm{~ms}$ after the start of injection. Reynolds number, Weber number and the density ratio of ambient gas to liquid fuel were included in the correlation while temporal information was not considered. Zhang et al. [16] further developed this model by including temporal analysis and divided the correlation into two zones based on the break-up time. However, the dimensionless correlations from previous works $[15,16]$ were developed at room temperature conditions, and evaporation due to the influence of ambient gas temperature was not considered. Further, all these models were developed under the ambient environment of air for non-evaporative conditions and nitrogen $\left(\mathrm{N}_{2}\right)$ for evaporative conditions. This work fills the gap with developed regression models for both liquid and vapor penetration length, focusing on the volatile gasoline spray at evaporative conditions.

Payri et al. [11] compared liquid penetration length for a singlehole diesel spray in inert ambient gas $\mathrm{N}_{2}$ and $\mathrm{SF}_{6}$ environments, and it was reported that the penetration length in $\mathrm{SF}_{6}$ was found to be longer than in $\mathrm{N}_{2}$. One reason reported was the difference in pressure drop, and the other was that more likely cavitation might take place with $\mathrm{SF}_{6}$ ambient condition. This shows that there is an apparent influence of ambient gas composition on spray penetration. Exhaust gas recirculation (EGR) is used to reduce $\mathrm{NO}_{\mathrm{x}}$ emissions in compression ignition engines [17]. By applying EGR, the exhaust gas displaces the fresh air entering the combustion chamber as a consequence the ambient gas composition is altered. It was recently reported that to achieve high gross indicated efficiency in GCI engines, high EGR up to $50 \%$ is used [18]. This indeed demonstrates that there is a need for understanding the spray penetration behavior under different ambient gas compositions. Therefore, in this study, the influence of ambient gas composition on spray tip penetration in both liquid and vapor phase at evaporative conditions has been studied, which was not reported earlier. Two different ambient gas composition was used to simulate no EGR condition and high EGR conditions, respectively. Then a temporal regression model has been developed by taking into account for ambient gas density, temperature, pressure difference for different ambient gas compositions.

\section{Experimental setup}

\subsection{Constant volume combustion chamber (CVCC) system}

A constant volume combustion chamber was used to simulate highpressure high-temperature engine related conditions, which is widely used by researchers for spray characterization [19-21]. It has the advantages of full control, well-specified boundary conditions, good optical access, and isolate the turbulence and swirl motions caused by the engine reciprocating motion. These advantages benefit not only for spray model development but also develop a fundamental understanding of the physical behavior of the spray event. The CVCC at KAUST Spray Lab is capable of handling 150 bar peak pressure. Premixed gas preparation, pre-burn initiation, fuel injection activation, and high-speed imaging are automated through in-house LabVIEW program such that run to run variation due to the anthropic operation is minimized. The whole system is schematically shown in Fig. 1. Pre-burn gas components were firstly mixed in an accumulator and then pushed into the CVCC. The gas mixture was ignited by a spark plug such that high pressure and high temperature is formed. Due to heat loss, preburn gas product pressure and temperature will decrease with time. Then the injection is triggered with a carefully selected delay after spark ignition, such that a desired ambient gas pressure and the temperature is achieved. The injector is mounted horizontally, and two quartz windows of diameter $\phi 100 \mathrm{~mm}$ are installed orthogonal to the injector axis give access to optical diagnostics like shadowgraph and diffused back illumination (DBI).

\subsection{Fuel injection system}

A closed water circulation connected with a heat exchanger was provided around the injector body to control the fuel temperature. The injector used in this study is an Aramco customized ten holes solenoid injector specially designed for GCI applications. The maximum injection pressure is rated at 500 bar, which is much higher than that of commercial market GDI injectors. The injector's orifice diameter is $0.165 \mathrm{~mm}$ and spray designed included angle is $110^{\circ}$. National Instrument DIDS 2003 system is used for injector trigger to control the 


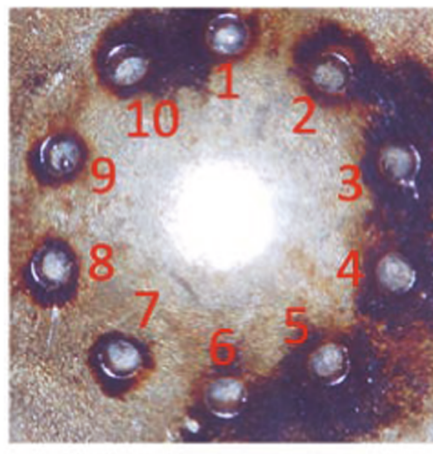

(a)

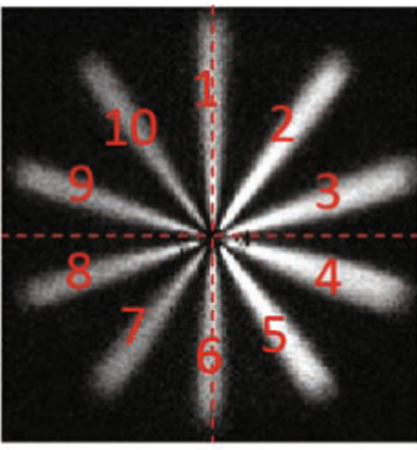

(b)

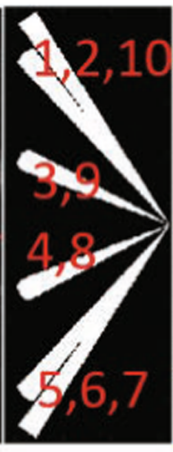

(c)

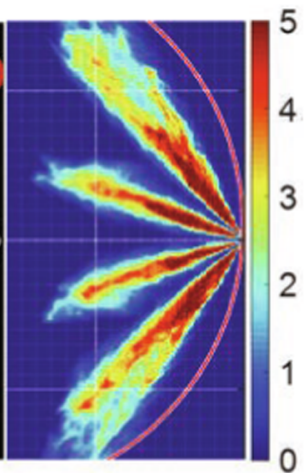

(d)

Fig. 2. (a) Orientation of ten nozzle holes; (b) Front view of spray from Mie-scattering; (c) Side view from CAD model; (d) Side view from diffused back illumination (DBI) image.

Table 1

Properties of the studied GCI fuel from Saudi Aramco.

\begin{tabular}{lll}
\hline Properties & Value & Unit \\
\hline RON & 77 & \\
Density @ $25^{\circ} \mathrm{C}$ & 707 & $\mathrm{~kg} / \mathrm{m}^{3}$ \\
Kinetic viscosity & $3.58 \times 10^{-4}$ & $\mathrm{Ns} / \mathrm{m}^{2}$ \\
Surface tension & $1.96 \times 10^{-2}$ & $\mathrm{~N} / \mathrm{m}$ \\
Final boiling point & 180.9 & ${ }^{\circ} \mathrm{C}$
\end{tabular}

excitation duration. An air driven liquid pump is used to pressurize the fuel. The dynamic injection pressure is measured using a Kistler 4067E piezoresistive pressure sensor on the high-pressure line at $70 \mathrm{~mm}$ from the injector end similar to the ECN community [19]. The orientation of the ten plumes was arranged in such a way that two of the plumes are located at the central plane top and bottom, respectively, and the others are distributed symmetrically, shown in Fig. 2. The fuel used in this study is high-reactivity gasoline with RON of 77 (GCI RON77) specially designed by Saudi Aramco for GCI applications. The properties of the fuel is shown in Table 1.

\subsection{Imaging system}

The optical alignment for vapor phase and liquid phase penetration length measurements are shown in Fig. 3. A high-speed monochrome Photron SA-X2 camera was used to capture spray event at 50,000 fps. Resolution for shadowgraph and DBI are $0.245 \mathrm{~mm} / \mathrm{pixel}$ and $0.195 \mathrm{~mm} /$ pixel, respectively. The images were then post-processed with an in-house built MATLAB code. The flow chart in Fig. 4 shows the sequence of image post-processing. Background subtraction, noise removal, binarization, boundary detection, and calibration are the main steps to get the spray characteristics from images. Fig. 5 shows the intermediate images and final spray boundary output obtained following the procedure illustrated in the flow chart. Shadowgraph postprocessing is similar, and the main difference is that background

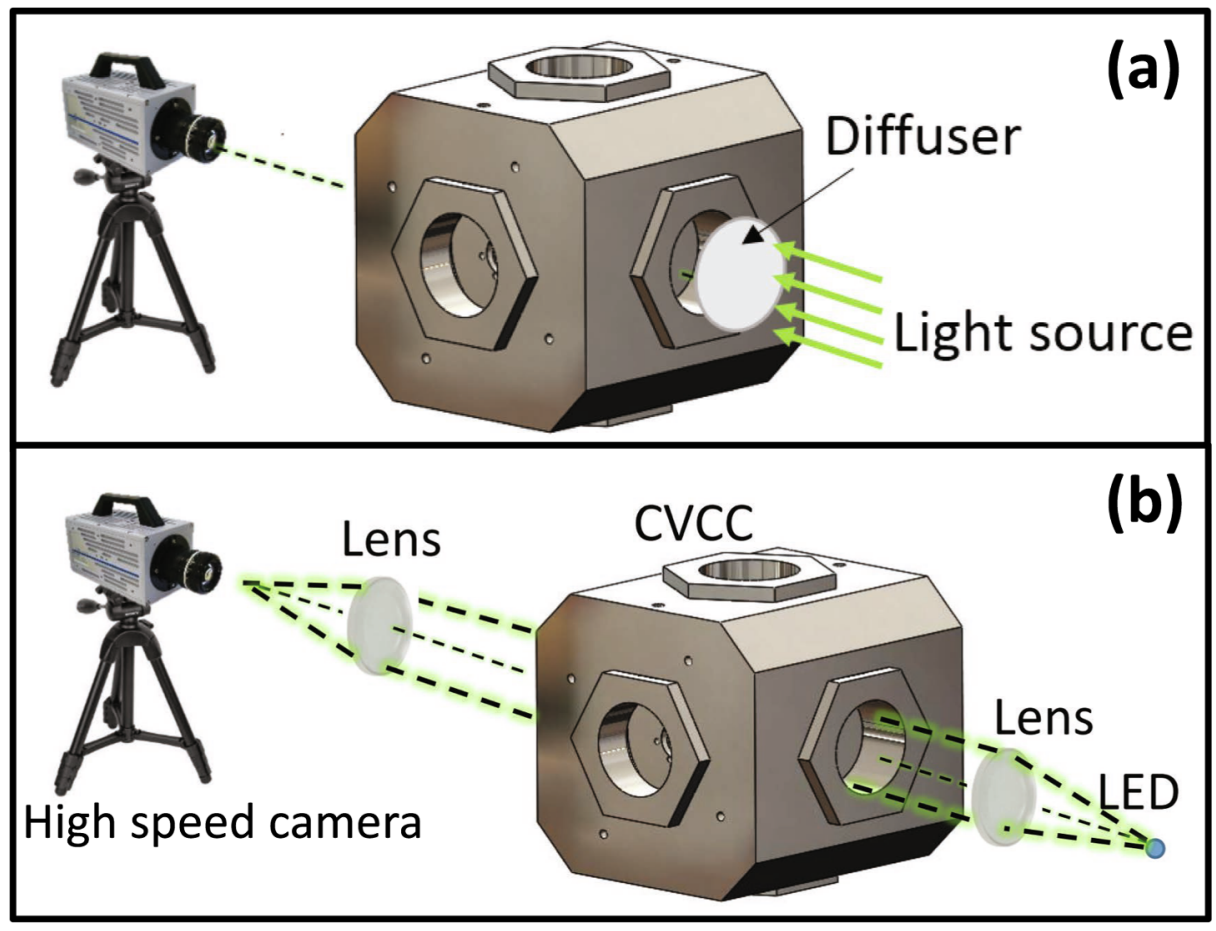

Fig. 3. Optical set-up for (a) Diffused backlit illumination (DBI) and (b) Shadowgraph techniques. 


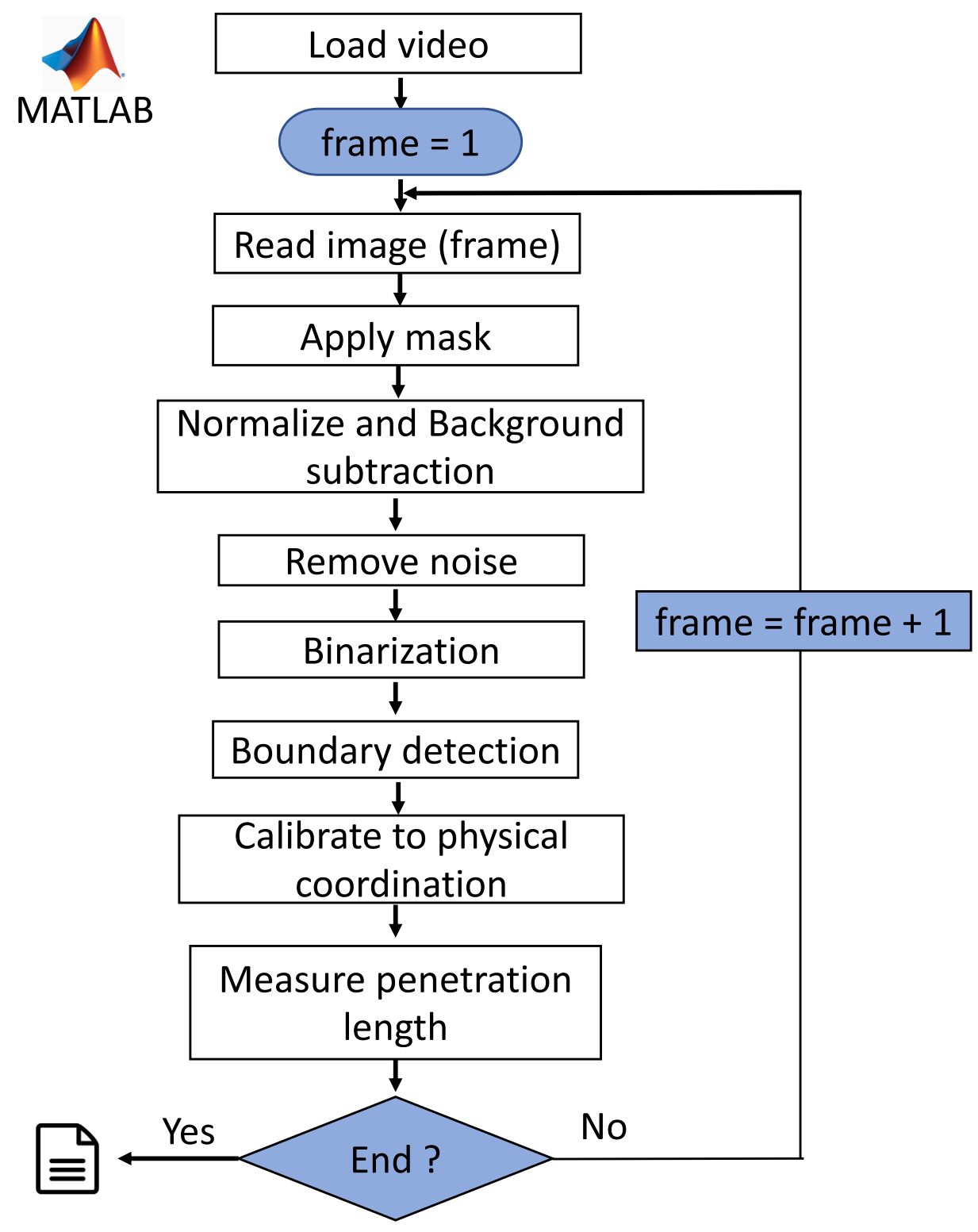

Fig. 4. Flowchart showing the sequence of image processing.

subtraction is done with frame $(n)$ - frame $(n-1)$ to avoid interference on edge detection from the ambient gas flow.

According to SAE J2715 standard [22], spray penetration length of the GDI injector is defined as the distance along the injector axis between the farthest distant point on spray boundary and injector tip. Fig. 6 shows how spray (a) vapor and (b) liquid penetration lengths were defined, respectively in this work. The farthest point is marked as red $^{1}$, and a white line perpendicular to the injector axis goes through it. The distance of this white line from the injector nozzle outlet is defined as the penetration length. Each condition was repeated three times, and an averaged penetration length was used for further regression study.

\section{Results and discussion}

The influence of different factors such as ambient gas temperature, pressure, gas composition, and injection pressure was studied. The oxygen concentration after the pre-burn event was maintained to be zero to investigate spray characteristics under the evaporative and nonreacting conditions. Two different initial gas compositions were used for the pre-burn event as shown in Table 2. The two different gas compositions are named as Gas No.1 and Gas No.2 and it will be used consistently throughout the paper from here on. The experimental test conditions are shown in Table 3. When different ambient gases were used, the ambient gas density and temperature were kept the same.

High reactivity gasoline of RON 77, specially designed by Saudi Aramco for GCI application, was used in this study. Fuel temperature was maintained at $90{ }^{\circ} \mathrm{C}$ throughout the experiments. Injector excitation duration was fixed at $1.75 \mathrm{~ms}$ for all cases. The rate of injection (ROI) is an essential input for CFD model validation and gives detailed information about the injection process. Bosch method [23] and momentum flux method [24] have been widely used for measuring ROI. The rate of injection and cumulative injection mass are measured at different injection pressures as shown in Fig. 7 by using momentum flux method. More details about the ROI measurements can be found in [25].

\subsection{Penetration length}

\subsubsection{Effect of injection pressure}

Fig. 8 shows the shadowgraph images for different injection 


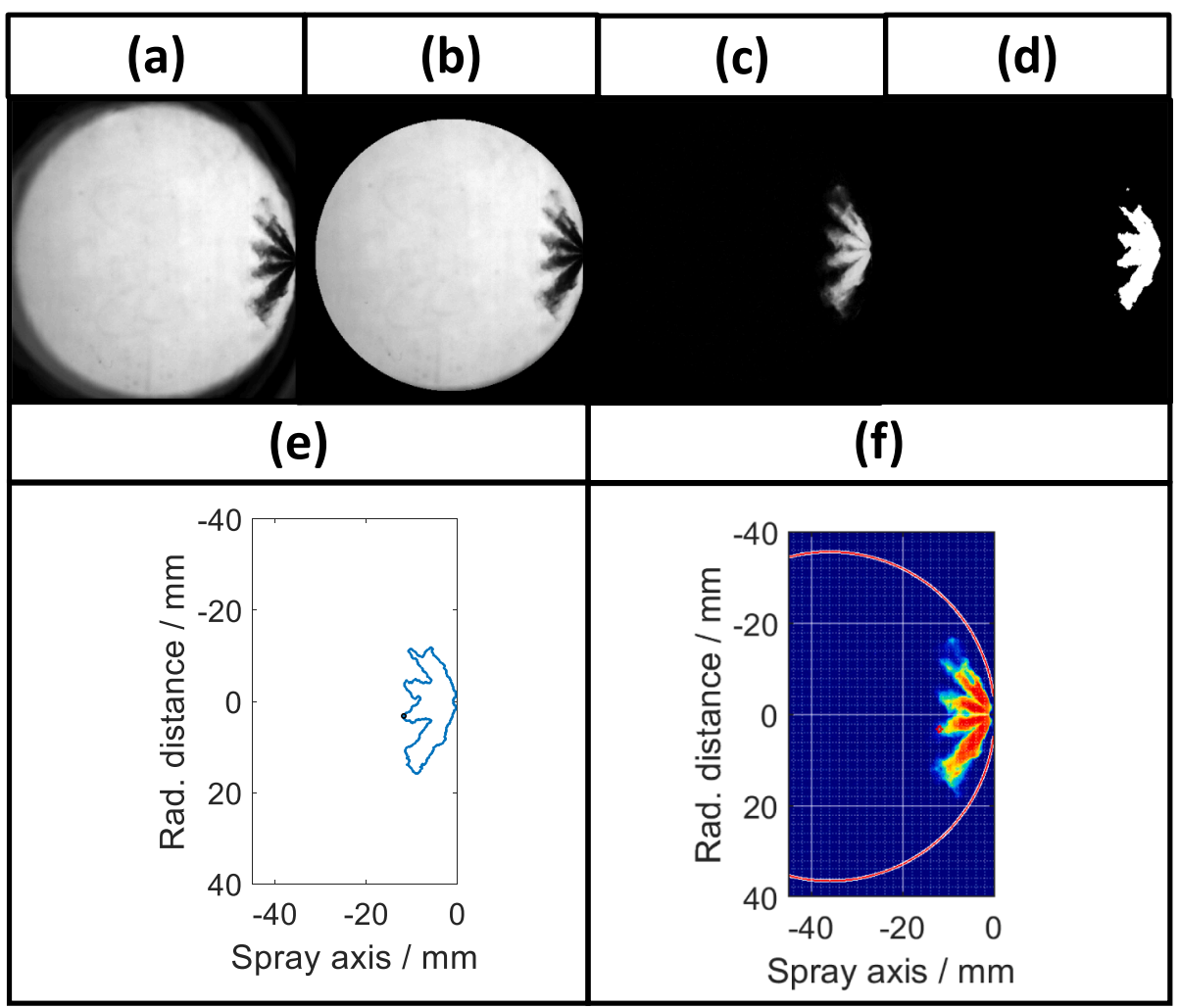

Fig. 5. Image post-processing sequence: (a) raw image, (b) masked image, (c) background subtracted and noise removed, (d) binary image, (e) boundary of spray, (f) pseudo color calibrated image.

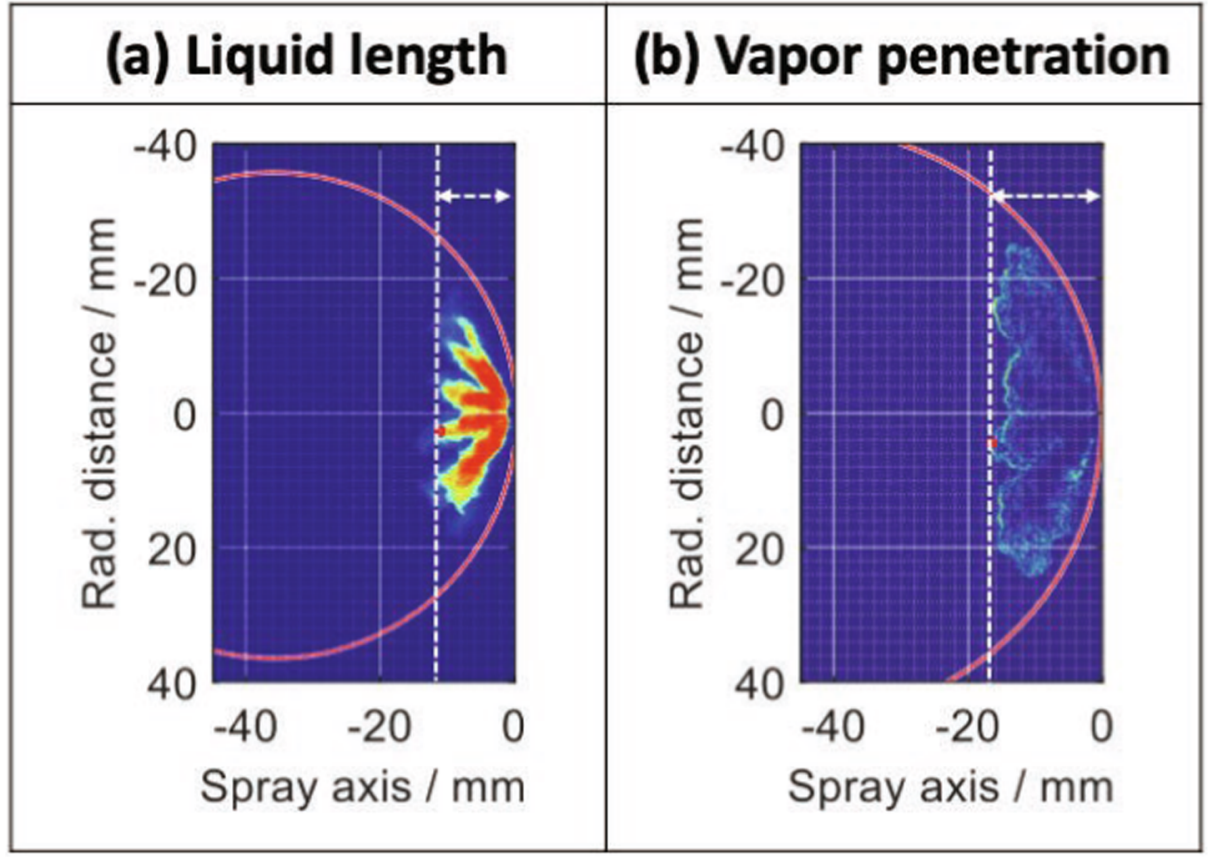

Fig. 6. Definition of (a) liquid and (b) vapor penetration length.

Table 2

Two different initial gas compositions by vol.\%.

\begin{tabular}{cccccc}
\hline Species & $\mathrm{H}_{2}$ & $\mathrm{C}_{2} \mathrm{H}_{2}$ & $\mathrm{O}_{2}$ & $\mathrm{~N}_{2}$ & $\mathrm{CO}_{2}$ \\
\hline Gas No.1 & 3 & 5 & 14 & 78 & 0 \\
Gas No.2 & 3 & 5 & 14 & 14 & 64 \\
\hline
\end{tabular}

pressures at $13.87 \mathrm{~kg} / \mathrm{m}^{3}$ ambient gas density and $500 \mathrm{~K}$ ambient gas temperature. When injection pressure increases from 100 bar to 450 bar, vapor penetration length increases. This increase in the vapor

\footnotetext{
${ }^{1}$ For interpretation of color in Fig. 6, the reader is referred to the web version of this article.
} 
Table 3

Experimental test conditions.

\begin{tabular}{|c|c|c|}
\hline Parameter & \multicolumn{2}{|c|}{ value } \\
\hline Injection pressure (bar) & \multicolumn{2}{|c|}{$100,300,450$} \\
\hline Ambient gas density $\left(\mathrm{kg} / \mathrm{m}^{3}\right)$ & 8.67 & 13.87 \\
\hline Ambient gas temperature $(K)$ & 800 & 500 \\
\hline Method & \multicolumn{2}{|c|}{ DBI, Shadowgraph } \\
\hline Initial gas composition (vol.\%) & \multicolumn{2}{|c|}{ Gas No.1, Gas No.2 } \\
\hline
\end{tabular}

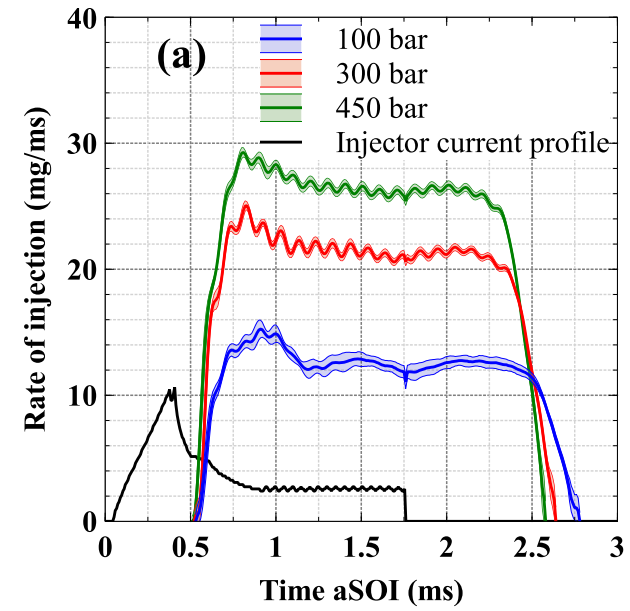

ambient temperature of $500 \mathrm{~K}$ is shorter because of higher ambient gas density whereas, the liquid penetration is longer due to lower ambient gas temperature for all injection pressure cases.

\subsubsection{Effect of ambient gas compositions}

Fig. 12 shows the effect of ambient gas composition on liquid and vapor penetration for different injection pressure and ambient density and temperature. For vapor phase, spray penetration behaves almost the same for two different gases. For liquid phase, gas composition with higher molecular weight (Gas No.2) shows longer liquid penetration length similar to results found in literature [11]. The reason for the longer liquid penetration length under ambient gas with high molecular weight is that the ambient gas pressure is lower when the molecular weight is higher for the same density and temperature. Thus pressure drop on the nozzle is higher, which results in higher momentum. Fig. 13

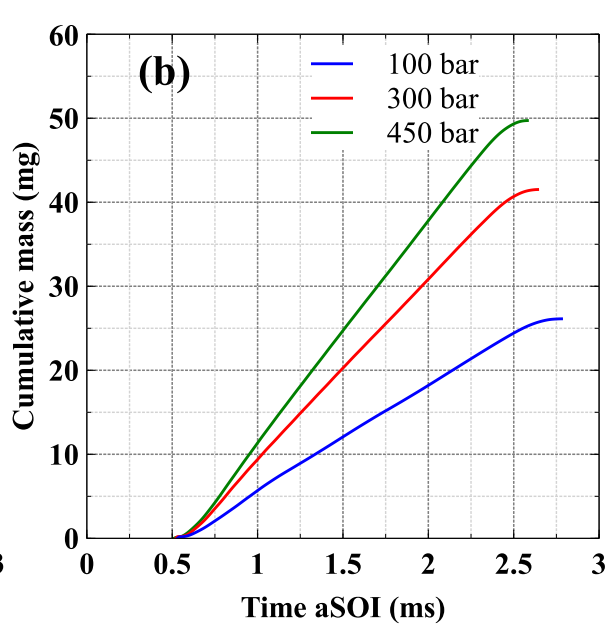

Fig. 7. Rate of injection and cumulative mass at different injection pressures [26] (back pressure 1 bar, duration $1.75 \mathrm{~ms}$ ).

penetration length is due to the increase in momentum.

Fig. 9 shows the liquid phase DBI images for different injection pressures. It can be seen that the liquid penetration at an early stage, for instance, $0.1 \mathrm{~ms}$ aSOI, increases with injection pressure. However, at the later stage, for example, at 0.5 and $1 \mathrm{~ms}$ aSOI, liquid penetration length is almost the same for all the injection pressures. In the early stage, the momentum controls the liquid penetration length and velocity, but in the later stage, it is driven by evaporation. Droplet travels from nozzle to this steady state spray front and diminishes due to evaporation. At higher injection pressure, a shorter time is required for spray droplets to evaporate, because of the enhanced liquid break-up, and smaller droplets formation. A smaller droplet size leads to the bigger surface area to volume ratio, which leads to faster evaporation. Another reason could be the higher relative velocity to ambient gas, which also results in enhanced evaporation at higher injection pressures. Fig. 10 compares the influence of injection pressure on liquid and vapor penetration length. It is interesting to note that for the liquid phase, the impact of injection pressure on the quasi-steady state penetration length is marginal, which was also observed on ECN spray G [27].

\subsubsection{Effect of ambient gas density and temperature}

Fig. 11 shows a comparison between two different ambient gas conditions. Shaded error band represents the standard deviation of three repeats. At different injection pressures, the ambient gas conditions show similar effects. It is interesting to note that the vapor penetration for a case of the ambient density of $13.87 \mathrm{~kg} / \mathrm{m}^{3}$ and the shows the image comparison between the liquid and vapor phase penetration for injection pressure of 450 bar, ambient density of 13.87 $\mathrm{kg} / \mathrm{m}^{3}$ and ambient temperature of $500 \mathrm{~K}$. It can be seen that as explained earlier, the liquid penetration under high molecular weight ambient gas is longer than in the other gas composition. However, the vapor phase penetration shows no significant differences under both ambient gas compositions.

\subsection{Prediction correlations}

\subsubsection{Vapor penetration}

Fig. 14 shows the logarithmic plot of vapor penetration length with Time aSOI. Unlike the two zones separated by the so-called "transition time" or "break-up time" reported in literature $[11,13,19]$, vapor phase penetration length in logarithmic scale shows excellent linear behavior in the entire injection duration. Thus a single prediction formula for entire injection duration is developed as shown in the following Eq. (1).

$S_{v}(t)=k \cdot(\Delta P)^{a} \cdot t^{b}$

where $S_{v}$ is the vapor penetration length, $t$ is the time after start of injection, $k$ is a coefficient and it's a function of ambient gas density $\left(\rho_{a}\right)$, and $\Delta P$ is the pressure difference $\left(\Delta P=P_{i n j}-P_{a m b}, P_{i n j}\right.$ is the injection pressure and $P_{a m b}$ is the ambient gas pressure).

Table 4 shows that higher ambient gas density has a smaller coefficient $k\left(\rho_{a}\right)$, which is reasonable and matches with experiment results. Based on the correlation obtained (Eq. (1)), comparison of prediction and experiment data are plotted in Fig. 15. It shows good confidence in 


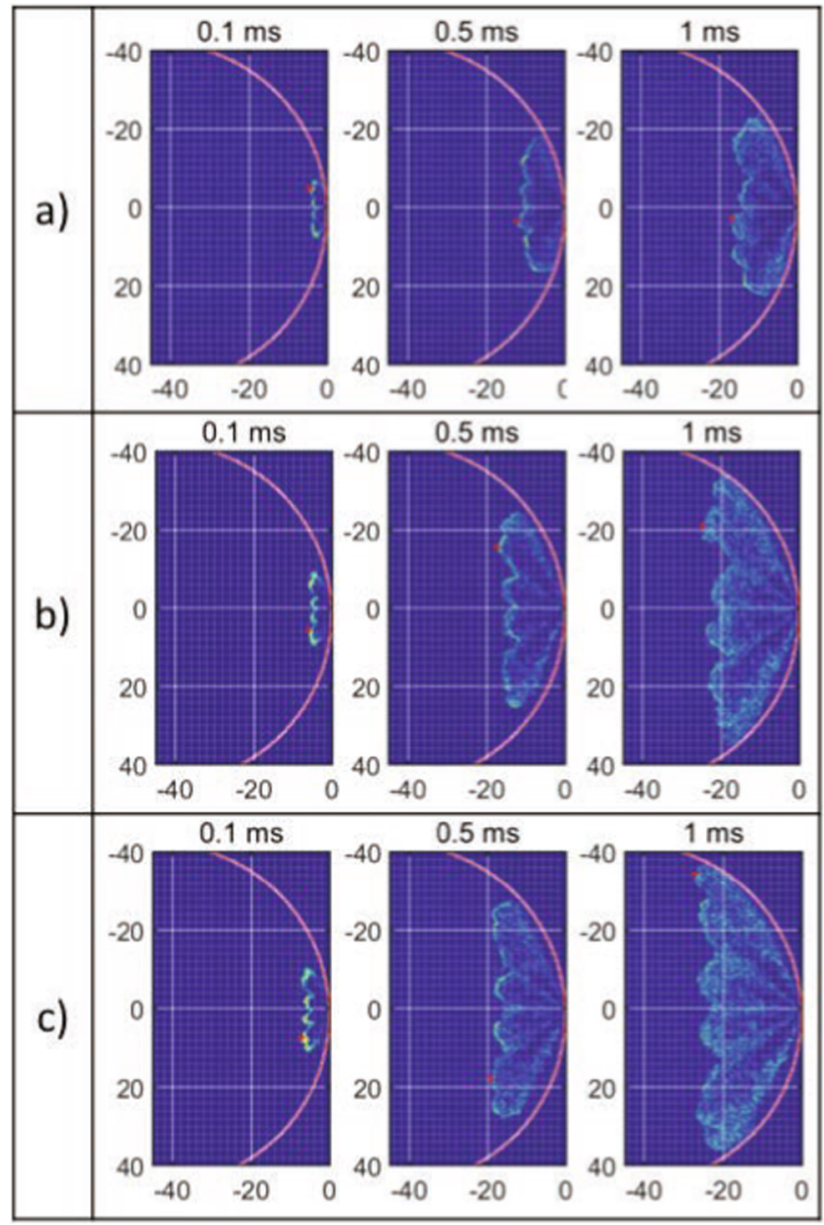

Fig. 8. Shadowgraph image sequences for different injection pressures of (a) 100 bar, (b) 300 bar, (c) 450 bar at ambient gas composition - Gas No.1; ambient density $-13.87 \mathrm{~kg} / \mathrm{m}^{3}$, ambient temperature $-500 \mathrm{~K}$.

the correlation.

\subsubsection{Liquid penetration}

Liquid penetration length in logarithmic scale (Fig. 16) shows that the curves are separated into two regions at a certain time, which is named as "separation time $\left(t_{1}\right)$ " in this work. It should be noted that this "separation time $\left(t_{1}\right)$ " is not the "transition time" or "break-up time" for cold jet mentioned in literature $[11,13,19]$. This separation point is due to the evaporation of liquid under high ambient gas temperature. For simplification, the regions earlier and later than separation time $\left(t_{1}\right)$ are linearly fitted respectively. Separation time $\left(t_{1}\right)$ advances with increasing injection pressure and increasing ambient gas temperature, similar trend was found by Payri et al. [28] for evaporative diesel spray. When the injection pressure is higher, droplet size formed are smaller thus droplet evaporates faster and the separation point advances. When the ambient gas temperature is higher, droplets also diminishes faster and leads to the advance of the separation point. Fig. 17 shows an example on how the $t_{1}$ is defined and penetration curve is piece-wise fitted. The same procedure is used for all the other data sets to arrive at the Eq. (2) and (3).

$\begin{array}{ll}S_{l}=k_{1} \cdot(\Delta P)^{a} \cdot t^{b} & t<t_{1} \\ S_{l}=k_{2} \cdot(\Delta P)^{a} \cdot t^{b} & t>t_{1}\end{array}$

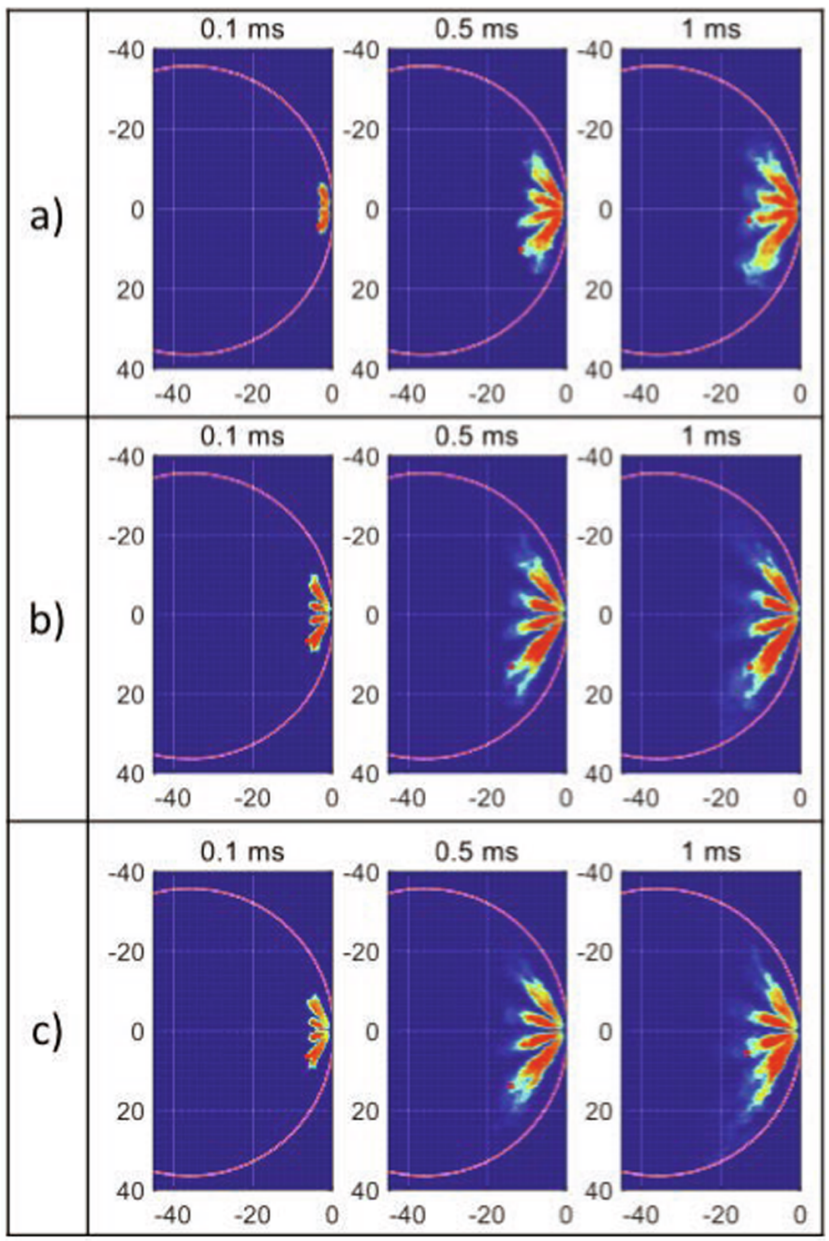

Fig. 9. DBI image sequences for different injection pressures of (a) $100 \mathrm{bar}$, (b) 300 bar, (c) 450 bar at ambient gas composition - Gas No.1; ambient density $13.87 \mathrm{~kg} / \mathrm{m}^{3}$, ambient temperature $-500 \mathrm{~K}$.

where $S_{l}$ is the liquid penetration length, $t$ is the time after start of injection, $k_{1}$ is a coefficient and it's a function of ambient gas density $\left(\rho_{a}\right)$ and ambient gas temperature $\left(T_{a}\right), k_{2}$ is a coefficient and it's a function of ambient gas density $\left(\rho_{a}\right)$, ambient gas temperature $\left(T_{a}\right)$ and ambient gas composition (Gas) and $\Delta P$ is the pressure difference $\left(\Delta P=P_{i n j}-P_{a m b}, P_{i n j}\right.$ is the injection pressure and $P_{a m b}$ is the ambient gas pressure).

Eqs. (2) and (3) shows the correlation in the different regions separated by the separation point $\left(t_{1}\right)$, and their corresponding coefficients are listed in Table 5. For the region before separation point, the two different ambient gases behave the same as it is shown in Fig. 12. Therefore, the gas component is not considered in the coefficient $k_{1}$. But it includes the influence of ambient gas density and gas temperature. In this study, ambient gas density and temperature are not isolated, which requires further investigation in the future. For the region later than separation point, ambient gas compositions affect penetration length as the pressure drop on the nozzle is different with different gas compositions. Therefore, the coefficient $k_{2}$ is influenced by ambient gas density, temperature, and compositions.

The exponential " $a$ " obtained in this study in the region earlier than separation point $\left(t_{1}\right)$ is similar to the power of Weber number $\left(t \geqslant t_{b}, R \geqslant 12500\right)$ reported by Zhang et al. [16], although the correlation developed by them is for cold jet, using a multi-hole diesel injector, and different fuel. The exponential " $b$ " $(0.646)$, is also similar to 

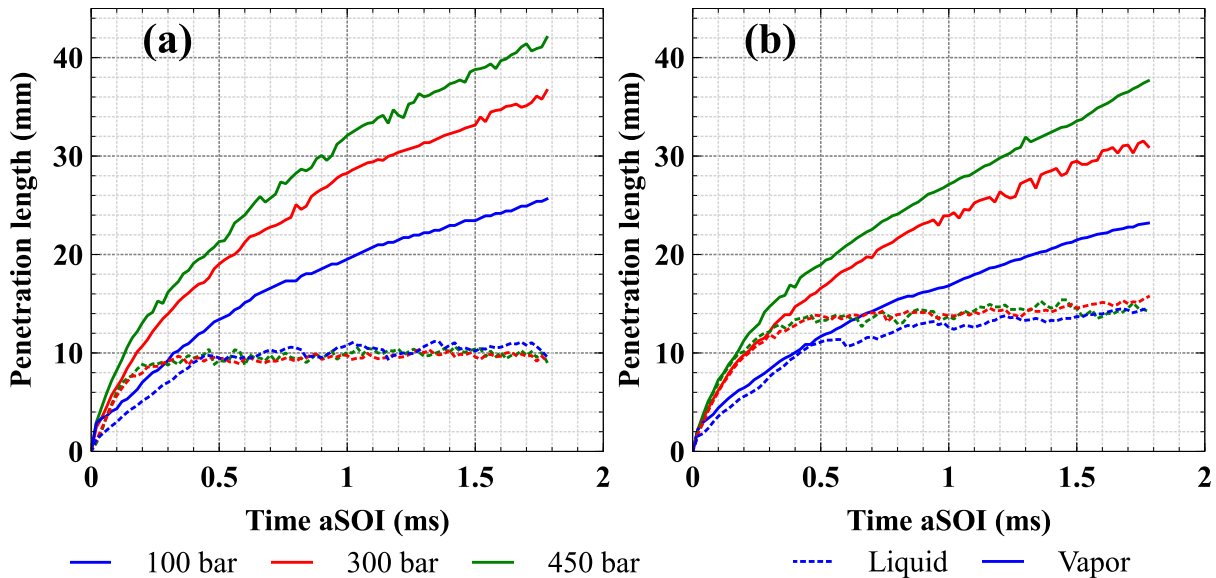

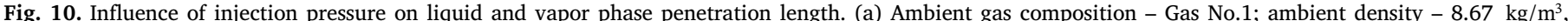
ambient temperature - $800 \mathrm{~K}$ (b) Ambient gas composition - Gas No.1; ambient density - $13.87 \mathrm{~kg} / \mathrm{m}^{3}$, ambient temperature - $500 \mathrm{~K}$.

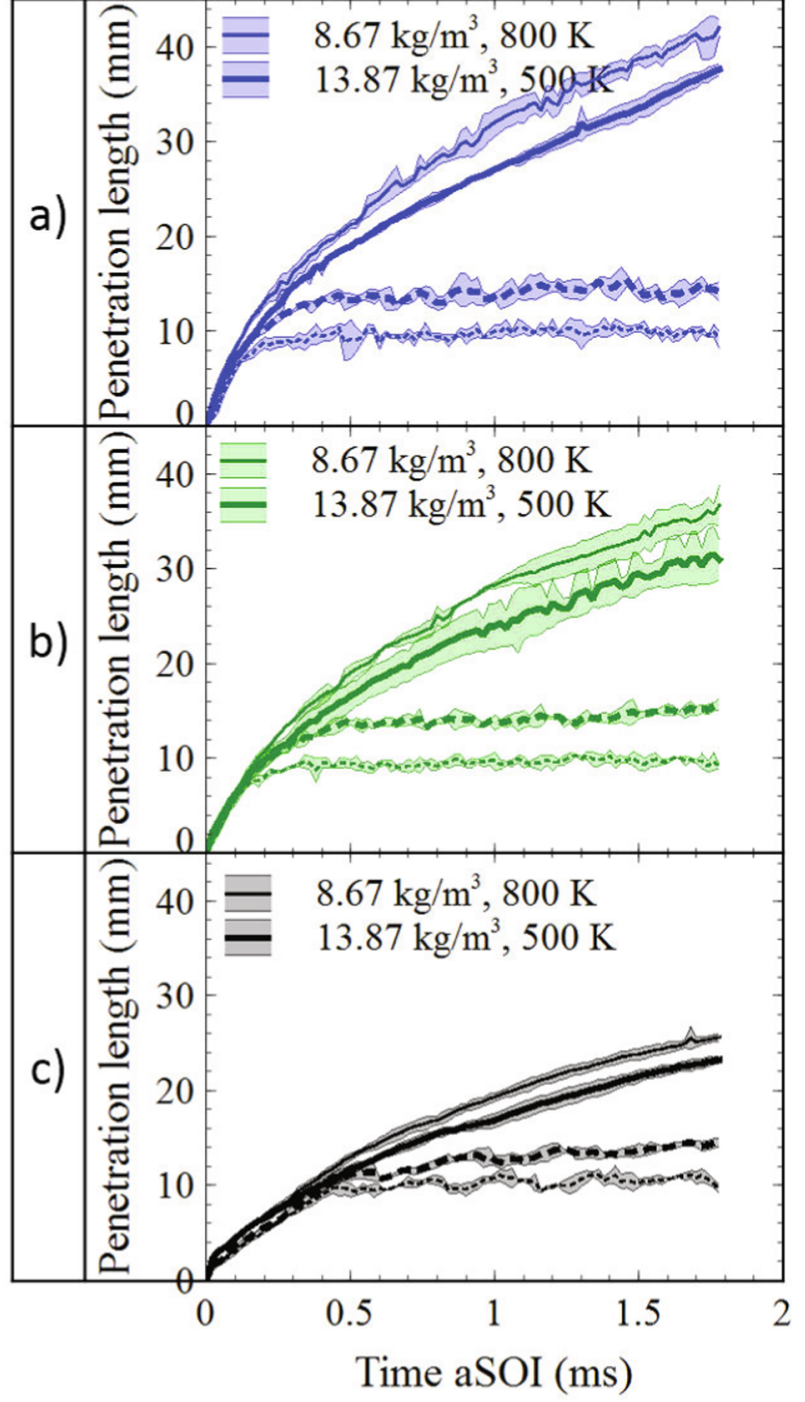

Fig. 11. Influence of ambient gas density and temperature for different injection pressures of (a) 450 bar injection pressure; (b) 300 bar injection pressure; (c) 100 bar and ambient gas composition - Gas No.1.

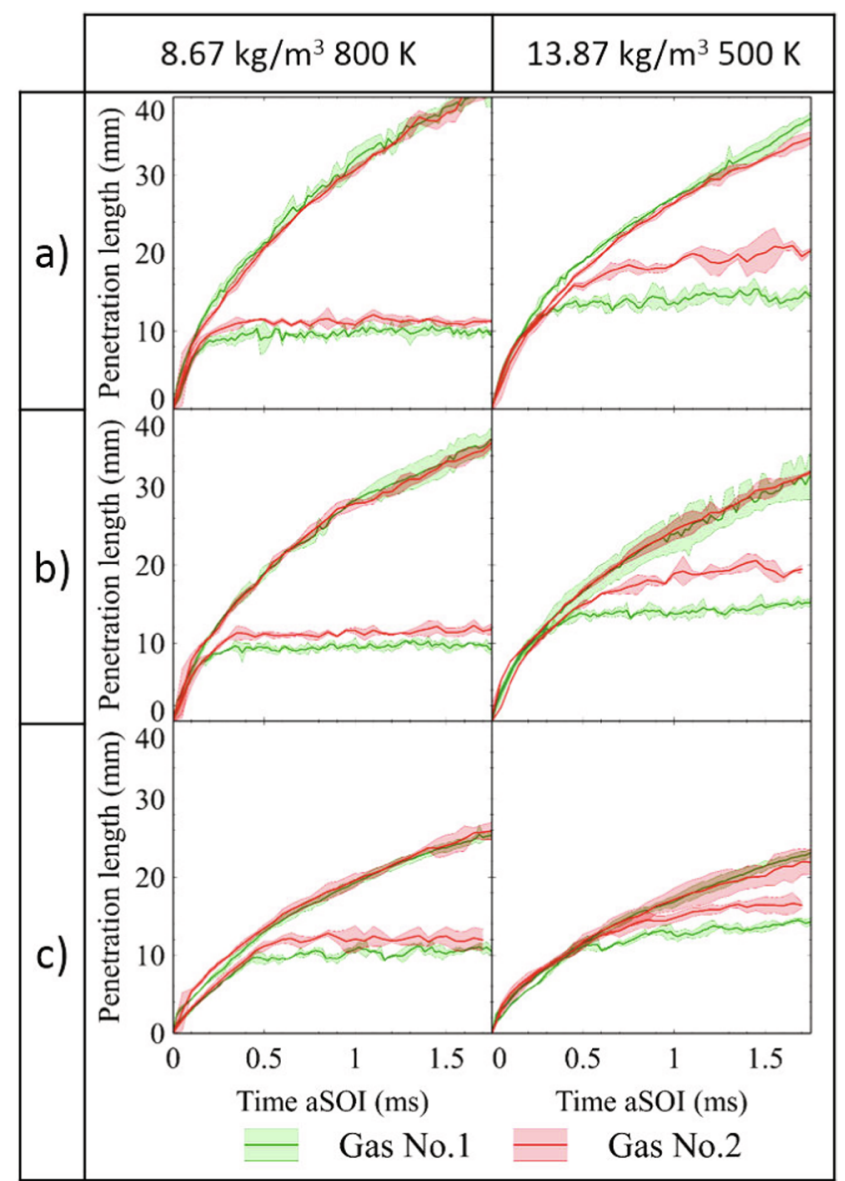

Fig. 12. Influence of ambient gas compositions for different injection pressures of (a) 450 bar injection pressure; (b) 300 bar injection pressure; (c) 100 bar and ambient gas densities of 8.67 and $13.87 \mathrm{~kg} / \mathrm{m}^{3}$ and temperatures of 800 and $500 \mathrm{~K}$ respectively. 


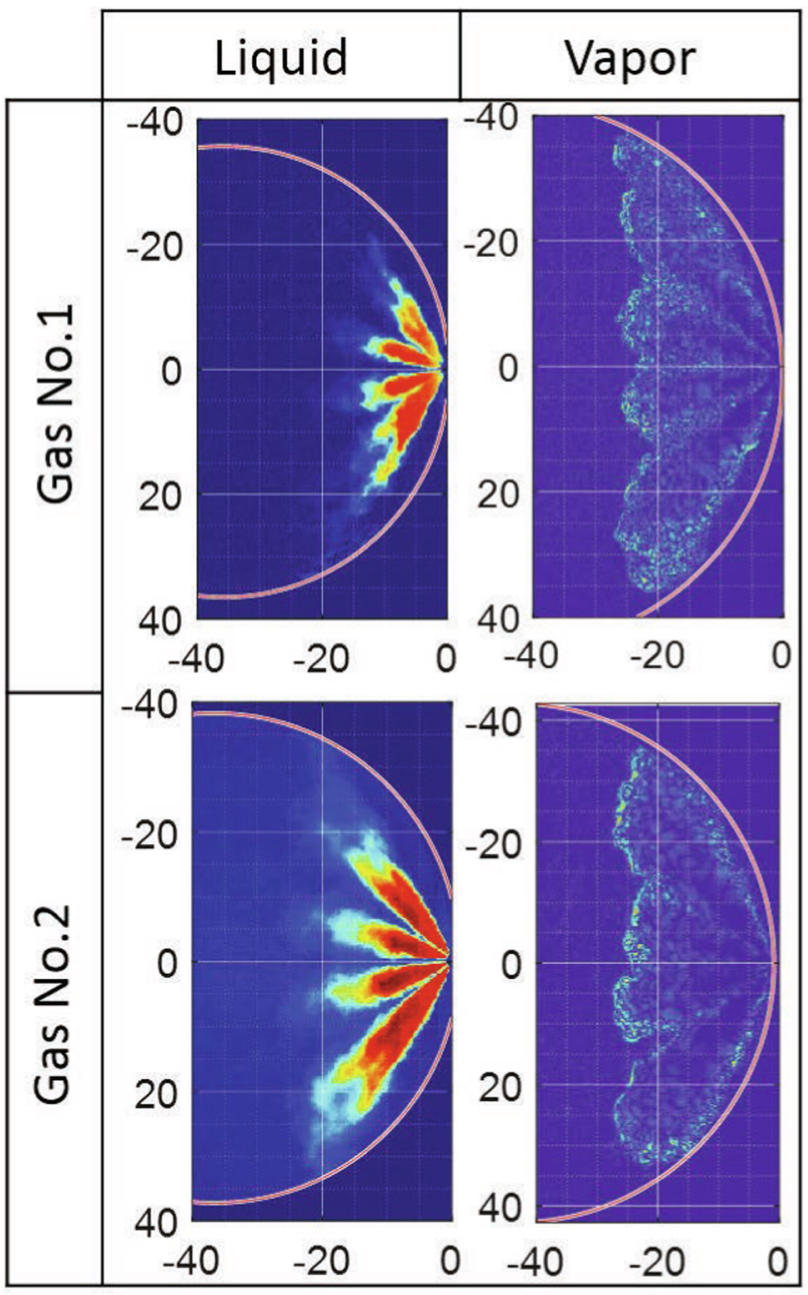

Fig. 13. Influence of ambient gas compositions on liquid and vapor penetration for injection pressure of $450 \mathrm{bar}$, ambient gas density of $13.87 \mathrm{~kg} / \mathrm{m}^{3}$ and ambient temperature of $500 \mathrm{~K}$.

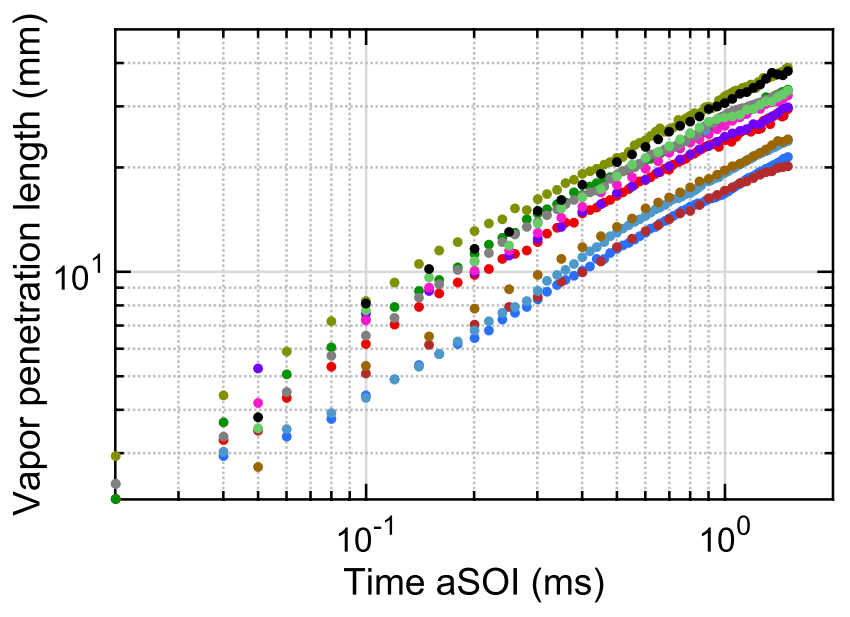

Fig. 14. Vapor penetration length in logarithmic scale.

Table 4

Ambient gas density dependent coefficient, Eq. (1).

\begin{tabular}{llll}
\hline Eq. (1) & $\mathrm{k}$ & $a$ & $b$ \\
\hline $13.87 \mathrm{~kg} / \mathrm{m}^{3}, 500 \mathrm{~K}$ & 4.9545 & 0.28 & 0.5514 \\
$8.67 \mathrm{~kg} / \mathrm{m}^{3}, 800 \mathrm{~K}$ & 5.6532 & & \\
\hline
\end{tabular}

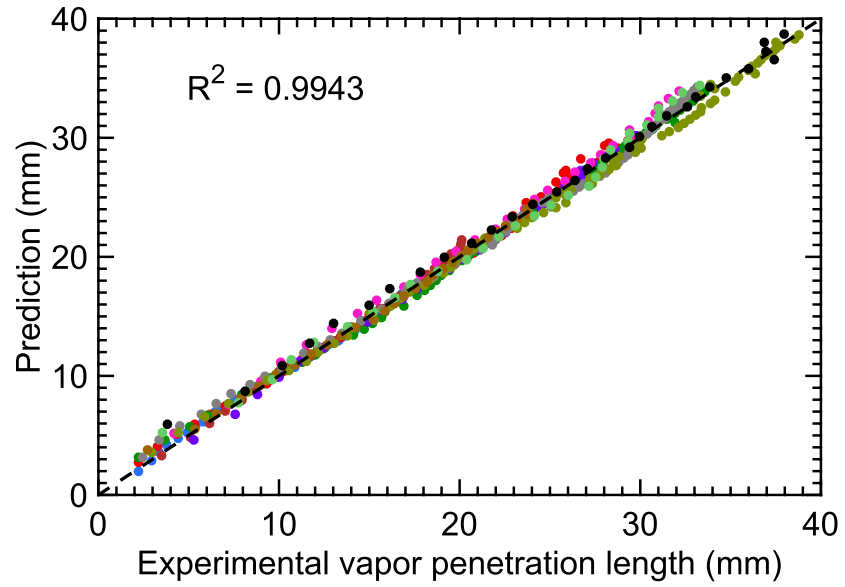

Fig. 15. Comparison of prediction and experimental measurement for vapor penetration length.

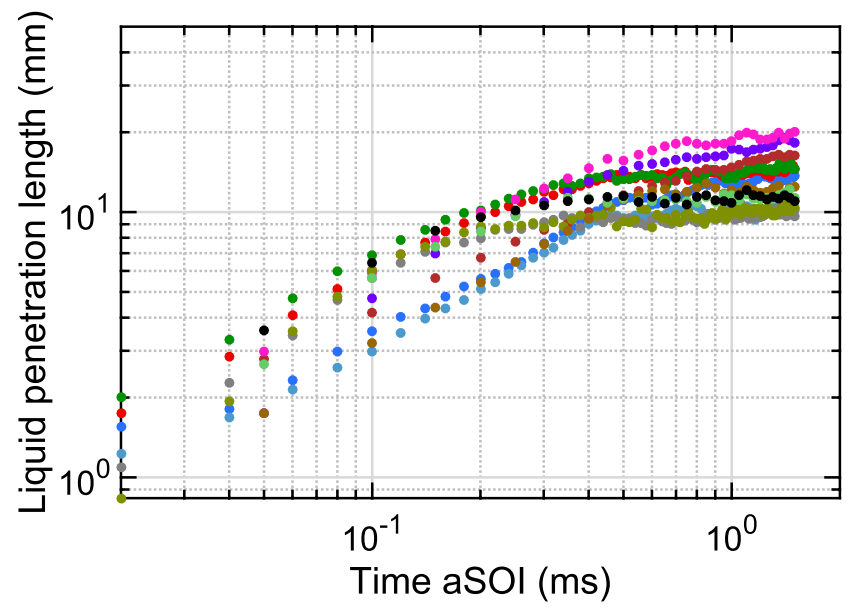

Fig. 16. Liquid penetration length in logarithmic scale.

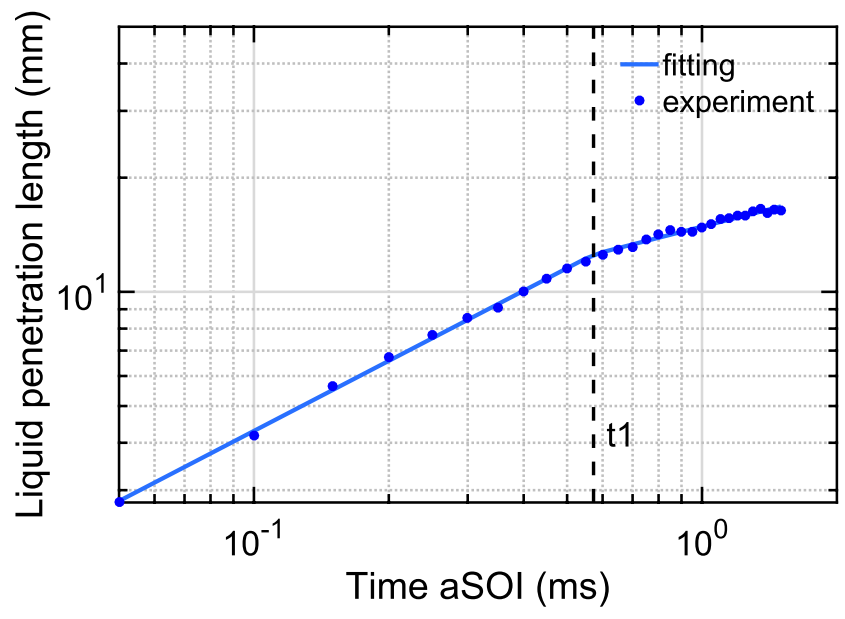

Fig. 17. Piece-wise fitting in logarithmic scale.

0.638 obtained in [16] for $\left(t \geqslant t_{b}\right)$. This comparison between current study and study by Zhang et al. [16] shows that the results for $t<t_{1}$ obtained in this work is comparable with the zone $\left(t \geqslant t_{b}\right)$ in literature. Fig. 18 shows the comparison between correlation prediction and experimental data. Black dots represents data earlier than $t_{1}$ and red dots for data later than $t_{1}$. It shows good confidence of the correlation developed in this study for high injection pressure gasoline multi-hole injector. 
Table 5

Coefficient for liquid penetration correlation.

\begin{tabular}{|c|c|c|c|c|}
\hline Eq. (2) & Gas & $k_{1}$ & $\mathrm{a}$ & $\mathrm{b}$ \\
\hline $13.87 \mathrm{~kg} / \mathrm{m}^{3}, 500 \mathrm{~K}$ & - & 4.1779 & 0.318 & 0.646 \\
\hline $8.67 \mathrm{~kg} / \mathrm{m}^{3}, 800 \mathrm{~K}$ & - & 3.886 & & \\
\hline Eq. (3) & Gas & $k_{2}$ & $a$ & $b$ \\
\hline \multirow[t]{2}{*}{$13.87 \mathrm{~kg} / \mathrm{m}^{3}, 500 \mathrm{~K}$} & Gas No.1 & 8.3829 & 0.0903 & 0.1018 \\
\hline & Gas No.2 & 10.3112 & & \\
\hline \multirow[t]{2}{*}{$8.67 \mathrm{~kg} / \mathrm{m}^{3}, 800 \mathrm{~K}$} & Gas No.1 & 9.9752 & 0 & \\
\hline & Gas No.2 & 11.6373 & & \\
\hline
\end{tabular}

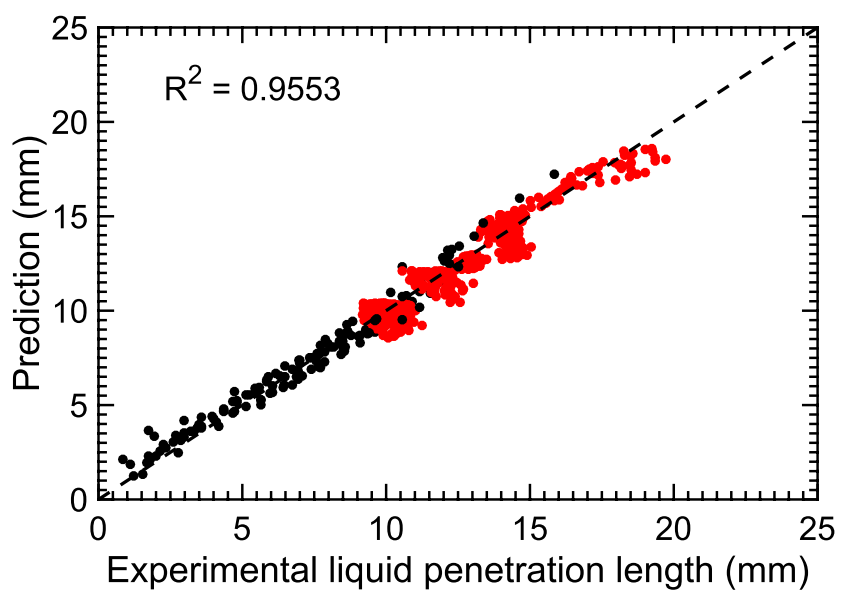

Fig. 18. Comparison of prediction and experimental measurement for liquid penetration length.
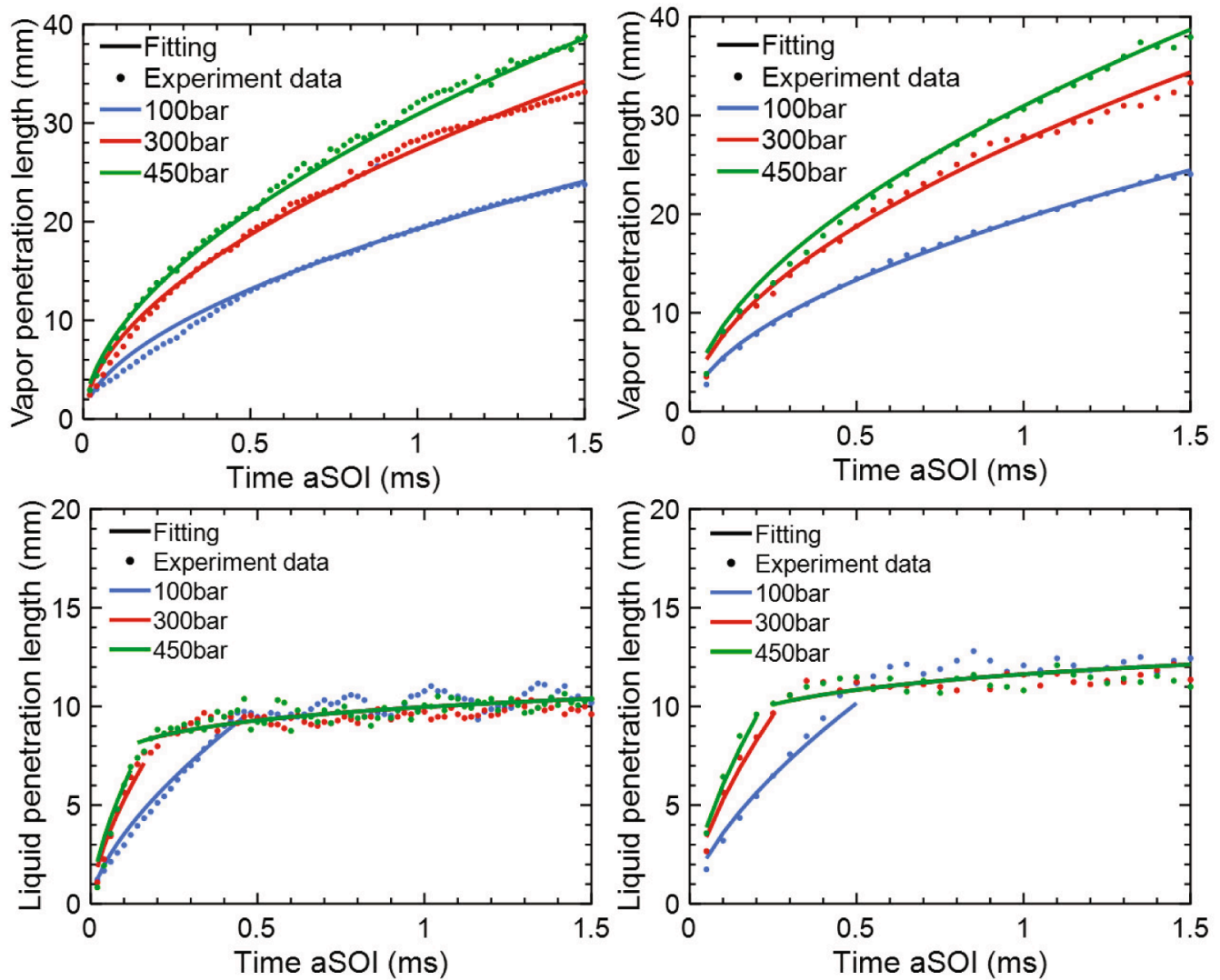

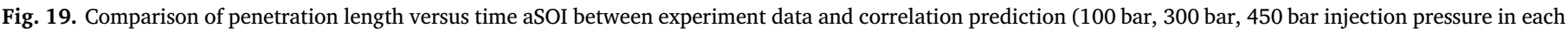
subplot). 
for separation time $t_{1}$, and further, isolate the influence of ambient gas density and temperature.

\section{Acknowledgments}

This work was sponsored by Saudi Aramco under the FUELCOM II program and by King Abdullah University of Science and Technology.

\section{References}

[1] J. Chang, G. Kalghatgi, A. Amer, Y. Viollet, Enabling high efficiency direct injection engine with naphtha fuel through partially premixed charge compression ignition combustion, Technical Report, SAE Technical Paper, 2012.

[2] J. Chang, G. Kalghatgi, A. Amer, P. Adomeit, H. Rohs, B. Heuser, Vehicle demonstration of naphtha fuel achieving both high efficiency and drivability with euro6 engine-out NOx emission, SAE Int. J. Engines 6 (2013) 101-119.

[3] J. Chang, Y. Viollet, A. Amer, G. Kalghatgi, Fuel economy potential of partially premixed compression ignition (PPCI) combustion with naphtha fuel, Technical Report, SAE Technical Paper, 2013b.

[4] C. Baumgarten, Mixture Formation in Internal Combustion Engines, Springer Science \& Business Media, 2006.

[5] N. Peters, J. Weber, The Effects of Spray Formation and Evaporation on Mixing, Auto-ignition and Combustion in Diesel Engines, THIESEL, Valencia, Spain, 2006.

[6] J.B. Heywood, et al., Internal combustion engine fundamentals, 1988.

[7] A.H. Lefebvre, V.G. McDonell, Atomization and Sprays, CRC Press, 2017.

[8] B. Mohan, W. Yang, S. kiang Chou, Fuel injection strategies for performance improvement and emissions reduction in compression ignition engines-a review, Renew. Sustain. Energy Rev. 28 (2013) 664-676.

[9] J. Dent, A basis for the comparison of various experimental methods for studying spray penetration, SAE Trans. (1971) 1881-1884.

[10] H. Hiroyasu, M. Arai, Structures of fuel sprays in diesel engines, SAE Trans. (1990) 1050-1061.

[11] R. Payri, F. Salvador, J. Gimeno, V. Soare, Determination of diesel sprays characteristics in real engine in-cylinder air density and pressure conditions, J. Mech. Sci. Technol. 19 (2005) 2040-2052.

[12] X. Wang, Z. Huang, O.A. Kuti, W. Zhang, K. Nishida, Experimental and analytical study on biodiesel and diesel spray characteristics under ultra-high injection pressure, Int. J. Heat Fluid Flow 31 (2010) 659-666.

[13] J. Gimeno, G. Bracho, P. Martí-Aldaraví, J.E. Peraza, Experimental study of the injection conditions influence over n-dodecane and diesel sprays with two ecn single-hole nozzles. Part I: inert atmosphere, Energy Convers. Manage. 126 (2016)
1146-1156.

[14] R. Payri, J. Gimeno, G. Bracho, D. Vaquerizo, Study of liquid and vapor phase behavior on diesel sprays for heavy duty engine nozzles, Appl. Therm. Eng. 107 (2016) 365-378.

[15] W. Zeng, M. Xu, M. Zhang, Y. Zhang, D.J. Cleary, Macroscopic characteristics for direct-injection multi-hole sprays using dimensionless analysis, Exp. Therm. Fluid Sci. 40 (2012) 81-92.

[16] G. Zhang, D.L. Hung, Temporal investigations of transient fuel spray characteristics from a multi-hole injector using dimensionless analysis, Exp. Therm. Fluid Sci. 66 (2015) 150-159.

[17] G.H. Abd-Alla, Using exhaust gas recirculation in internal combustion engines: a review, Energy Convers. Manage. 43 (2002) 1027-1042.

[18] N. Dimitrakopoulos, G. Belgiorno, M. Tunér, P. Tunestål, G. Di Blasio, Effect of egr routing on efficiency and emissions of a ppc engine, Appl. Therm. Eng. 152 (2019) $742-750$.

[19] L.M. Pickett, C.L. Genzale, G. Bruneaux, L.-M. Malbec, L. Hermant, C. Christiansen, J. Schramm, Comparison of diesel spray combustion in different high-temperature, high-pressure facilities, SAE Int. J. Engines 3 (2010) 156-181.

[20] Z. Wu, L. Wang, J.A. Badra, W.L. Roberts, T. Fang, Gdi fuel sprays of light naphtha, prf95 and gasoline using a piezoelectric injector under different ambient pressures, Fuel 223 (2018) 294-311.

[21] J. Liu, L. Feng, H. Wang, Z. Zheng, B. Chen, D. Zhang, M. Yao, Spray characteristics of gasoline/pode and diesel/pode blends in a constant volume chamber, Appl. Therm. Eng. (2019) 113850.

[22] D.L. Hung, D.L. Harrington, A.H. Gandhi, L.E. Markle, S.E. Parrish, J.S. Shakal, H. Sayar, S.D. Cummings, J.L. Kramer, Gasoline fuel injector spray measurement and characterization-a new sae j2715 recommended practice, SAE Int. J. Fuels Lubric. 1 (2009) 534-548.

[23] R. Payri, G. Bracho, J. Gimeno, A. Bautista, Rate of injection modelling for gasoline direct injectors, Energy Convers. Manage. 166 (2018) 424-432.

[24] F. Salvador, M. Carreres, D. Jaramillo, J. Martínez-López, Analysis of the combined effect of hydrogrinding process and inclination angle on hydraulic performance of diesel injection nozzles, Energy Convers. Manage. 105 (2015) 1352-1365.

[25] B. Mohan, J. Du, J. Sim, W.L. Roberts, Hydraulic characterization of high-pressure gasoline multi-hole injector, Flow Meas. Instrum. 64 (2018) 133-141.

[26] J. Du, B. Mohan, J. Sim, W.L. Roberts, Experimental study on the non-reacting spray characterization of gasoline compression ignition fuel, Energy Proc. 158 (2019) 1968-1973.

[27] R. Payri, F.J. Salvador, P. Martí-Aldaraví, D. Vaquerizo, Ecn spray g external spray visualization and spray collapse description through penetration and morphology analysis, Appl. Therm. Eng. 112 (2017) 304-316.

[28] R. Payri, J.S. Giraldo, S. Ayyapureddi, Z. Versey, Experimental and analytical study on vapor phase and liquid penetration for a high pressure diesel injector, Appl. Therm. Eng. 137 (2018) 721-728. 